\title{
Development of a coupled flow and solute transport modelling for Astaneh- Kouchesfahan groundwater resources, North of Iran.
}

\begin{abstract}
Astaneh-Kouchesfahan Plain is an important source of groundwater in Northern Iran. In the study area, rational management of groundwater resources requires a precise evaluation of groundwater flow and transport components. For this purpose, a 2-dimentional groundwater flow and solute transport model was developed and calibrated using PMWIN 5.3. Simulation results under steady-state and transient conditions show that the horizontal hydraulic conductivity values range from 1 to $23 \mathrm{~m} /$ day; and the specific yield values range between 0.03 and 0.25 . After construction groundwater flow model, in order to simulate and predict chloride transport in the study area, a 2-D solute transport model for the aquifer has been developed, calibrated and validated using MT3D. The predictive simulation from October 2009 to October 2012 shows that according to present recharge and discharge conditions, groundwater salinities will increase and in the mid and long-term, groundwater consumers will be facing a worse situation than the present.
\end{abstract}

Keyword: Groundwater simulation; Hydrogeology; Iran; MT3D; Numerical simulation; PMWIN; Flow modelling; Solute transport modelling; Hydraulic conductivity; Chloride transport; Groundwater salinity; Water quality; Water pollution; Groundwater quality; Groundwater pollution. 